\title{
The safety and feasibility of three-dimension single-port video-assisted thoracoscopic surgery for the treatment of early- stage lung cancer
}

\author{
Yiyang Wang, Zhexin Wang, Feng Yao \\ Department of Thoracic Surgery, Shanghai Chest Hospital, Shanghai Jiao Tong University, Shanghai, China \\ Contributions: (I) Conception and design: F Yao; (II) Administrative support: F Yao; (III) Provision of study materials or patients: Y Wang; (IV) \\ Collection and assembly of data: Y Wang; (V) Data analysis and interpretation: Z Wang; (VI) Manuscript writing: All authors; (VII) Final approval of \\ manuscript: All authors. \\ Correspondence to: Feng Yao, MD. Department of Thoracic Surgery, Shanghai Chest Hospital, Shanghai Jiao Tong University, No. 241 West Huaihai \\ Road, Shanghai 200030, China. Email: yaofeng6796678@126.com.
}

Background: Video-assisted thoracoscopic surgery (VATS) has been widely used in the lung resections.
Reports regarding three-dimension (3D) single-port VATS are very limited. The purpose of this study is to
evaluate the perioperative outcomes of 3D single-port VATS in a single medical center.
Methods: Totally 523 clinical stage I lung cancer patients underwent surgical resection through VATS
operation between September 2016 and October 2017 in our single institution were retrospectively collected
and 374 were enrolled. The comparison between 3D single-port VATS and conventional VATS (c-VATS),
single-port VATS was conducted focusing on intraoperative and postoperative outcomes. Continuous and
categorical variables were analyzed through SPSS software.
Results: The 3D singe-port VATS demonstrated no significant difference neither on the intraoperative
outcomes including the operative time and the intraoperative blood loss nor the postoperative outcomes
including the length of drainage duration and postoperative complications when against c-VATS and single-
port VATS. Besides, 3D singe-port VATS elucidated comparable ability of lymph node dissection with
c-VATS in subgroup analysis (P=0.192), both of which were better than single-port VATS group (P<0.001).
What's more, the rate of conversion as well as hospital stays of 3D single-port group were also comparable.
In subgroup analysis, 3D singe-port VATS also elucidated its safety and feasibility when dealing with routine
thoracic surgeries including lobectomy and segmentectomy.
Conclusions: 3D single-port VATS, integrating the advantages of single-port VATS and three-
dimensional vision of 3D VATS, is a safe and feasible technique and is promising for next-generation
thoracoscopic surgery.

Keywords: Three-dimension (3D); single-port; video-assisted thoracoscopic surgery (VATS); early-stage lung cancer

Submitted Oct 28, 2019. Accepted for publication Sep 10, 2020.

doi: $10.21037 /$ jtd-19-3465

View this article at: http://dx.doi.org/10.21037/jtd-19-3465

\section{Introduction}

The advent of video-assisted thoracoscopic surgery (VATS), a major part of minimally invasive surgery, has significantly altered respiratory surgical procedures $(1,2)$. VATS has been widely used and become the mainstream in the treatment of early-stage lung cancer patients due to its remarkable benefits, such as much smaller incision, reduced pain, and shorter hospital stay, on patients, compared to the traditional thoracotomy $(3,4)$. Based on the most popular conventional VATS (c-VATS) using 3 or 4 ports, more 


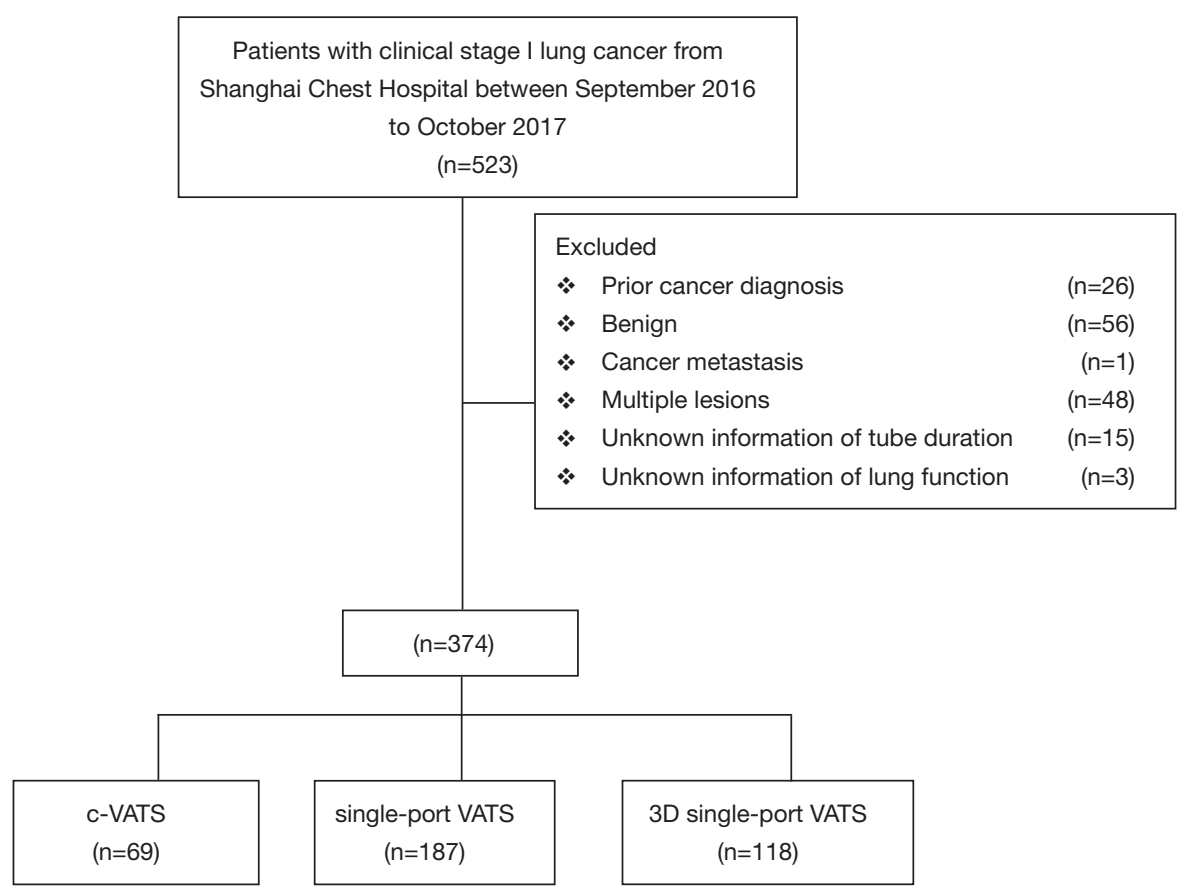

Figure 1 Study flowchart.

approaches have been developed in the field of thoracic surgery, such as two-ports, single-port, and three-dimension (3D) VATS as well as Davinci Robot, which show the similar or even better surgical outcomes. Since then, lung segmentectomy and surgery for advanced lung cancer have been reported using those approaches (5-7).

Recently, 3D single-port VATS, with some potential advantages such as less trauma and better vision, has been introduced in Shanghai Chest Hospital. However, reports regarding this approach are very limited. In the present study, we introduced our initial experience of using 3D single-port VATS to treat early-stage lung cancer.

We present the following article in accordance with the STROBE reporting checklist (available at http://dx.doi. org/10.21037/jtd-19-3465).

\section{Methods}

\section{Patient inclusion and exclusion criteria}

This retrospective study was approved by the Institutional Ethics Committee of Shanghai Chest Hospital [KS (Y) 1803], which was in line with the 1964 Helsinki Declaration (as revised in 2013). The written informed consent was not needed for this research. Patients with clinical stage I lung cancer undergoing surgical resection between September
2016 and October 2017 were included in this retrospective analysis. Those candidates would be excluded if they met the following exclusive criteria, (I) previous cancer diagnosis within 5 years; (II) benign lesions; (III) other cancer metastasis proven by final history; (IV) multiple primary lung cancers proven by final pathology (Figure 1).

We divided our candidates into three groups, c-VATS, single-port VATS and 3D single-port VATS groups. Specifically, 3D single-port group was defined as the patients receiving $3 \mathrm{D}$ single-port VATS during surgical resection. And the other two groups were the observations, which was defined as the candidates receiving conventional multi-port and single-port VATS treatments, respectively.

\section{Preoperative examination}

All these patients had the preoperative examination to evaluate the resectability and to exclude distant metastasis, including chest computed tomography (CT) scan, bronchoscopy, abdominal CT or ultrasonography examination, brain magnetic resonance imaging and whole-body bone scan. Mediastinoscopy or endobronchial ultrasound-guided trans-bronchial needle aspiration (EBUS-TBNA) was selectively performed in patients with enlargement of the lymph node, and those with suspected 
lymph node metastasis indicated by positron emission tomography (PET). Staging was performed according to the 8th TNM classification.

\section{Surgical operation of $3 D$ single-port VATS}

In 3D single-port VATS, an approximately 4-cm incision was made on the anterior (upper and lower lobectomy) or middle (lower lobectomy) axillary line (Figure $2 \mathrm{~A}$ ), followed by the attachment of a Protector. The procedure was a thoracoscope was mostly handled at an angle of more than 45 degrees from the chest wall. Surgery was performed using a 10 - or 5-mm 30-degree obliqueviewing thoracoscope and facing/inverted dual-monitors without any specific device. The Wrap Protector mini was used to open incisions, and a small rib Retractor was not used. The energy device, HARMONIC scalpel (Ethicon, USA) was used for mediastinal lymph node dissection. With 3D glasses, stereoscopic perception was given to enhance the feasibility and efficiency of surgical resection (Figure 2B). Data cable and optical fiber cable were in the same direction, presenting like a sector and extremely improving surgical flexibility and convenience and releasing assistant fatigue (Figure 2C). Various surgical factors (operative outcomes), the incidence of complications, postoperative complications, and 30-day mortality were all evaluated.

\section{Follow-up strategy and study endpoint}

The patients were scheduled for a first re-visit for evaluation of postoperative recovery at four weeks after operations. Information was obtained from patients through phone call and outpatient clinic re-visit records. Then, a follow-up visit was scheduled every 3-6 months for tumor evaluation after the first visit, by chest CT scans, abdominal sonography or CT, and serum tumor markers. Other examinations were performed according to the physicians if it is necessary.

In this study, our primary study endpoint was the intraoperative outcomes including operation time, blood loss, the number of dissected lymph node and the conversion to open thoracotomy. The secondary endpoint was the postoperative outcomes, which included the drainage duration, the length of hospital stays, the rate of postoperative complications and the rate of prolonged air leak. The postoperative complications were described according to the Common Terminology Criteria for Adverse Events Version (CTCAE) 5.0, including hyperpyrexia, air leak, bleeding, subcutaneous emphysema, infection, chylothorax, pulmonary atelectasis and arrhythmia. And the prolonged air leak was defined the time was more than 3 days after surgical resection.

\section{Statistical analysis}

Normally distributed continuous variables are presented as the mean $\pm \mathrm{SD}$, otherwise as the median and range, which were testified by the $t$ test. Categorical variables are shown as numbers and percentages, which were testified by the Pearson $\chi^{2}$ or Fisher's exact test. Statistical analyses were performed using SPSS software (version 19.0; IBM-SPSS, Inc., Chicago, IL, USA). The statistical significance was set as the two-sided $\mathrm{P}<0.05$ for our research analysis.

\section{Results}

\section{The clinicopathological characteristics of study cohort}

There were totally 523 clinical stage I lung cancer patients receiving radically surgical resection in Shanghai Chest Hospital and 374 cases were enrolled in our retrospective analysis,. including 69 patients with c-VATS, 187 with single-port VATS and 118 with 3D single-port VATS (Figure 1). All the baseline characteristics of the primary cohort were listed in Table 1.

\section{The analysis of perioperative clinical outcomes}

With respect to the comparison of intraoperative outcomes, the operative time and the intraoperative blood loss of $3 \mathrm{D}$ singe-port VATS demonstrated no significant difference when against c-VATS and single-port VATS, respectively. Inspiringly, our 3D singe-port VATS elucidated comparable ability of lymph node dissection with c-VATS in subgroup analysis $(\mathrm{P}=0.192)$, both of which presented more harvested lymph nodes when against single-port VATS group $(\mathrm{P}<0.001)$. What's more, the rate of conversion to open thoracotomy of our 3D single-port group was as low as the single-port VATS one, all of which was statistically less than c-VATS $(\mathrm{P}=0.022)$ (Table 2).

As for the postoperative outcomes, $3 \mathrm{D}$ singe-port VATS still performed similar length of drainage duration $(\mathrm{P}=0.109)$ as well as postoperative complications $(\mathrm{P}=0.998)$ in contrast with other two groups. Nevertheless, our 3D single-port VATS demonstrated similar hospital stays in comparison with c-VATS, all of which were statistically higher than 

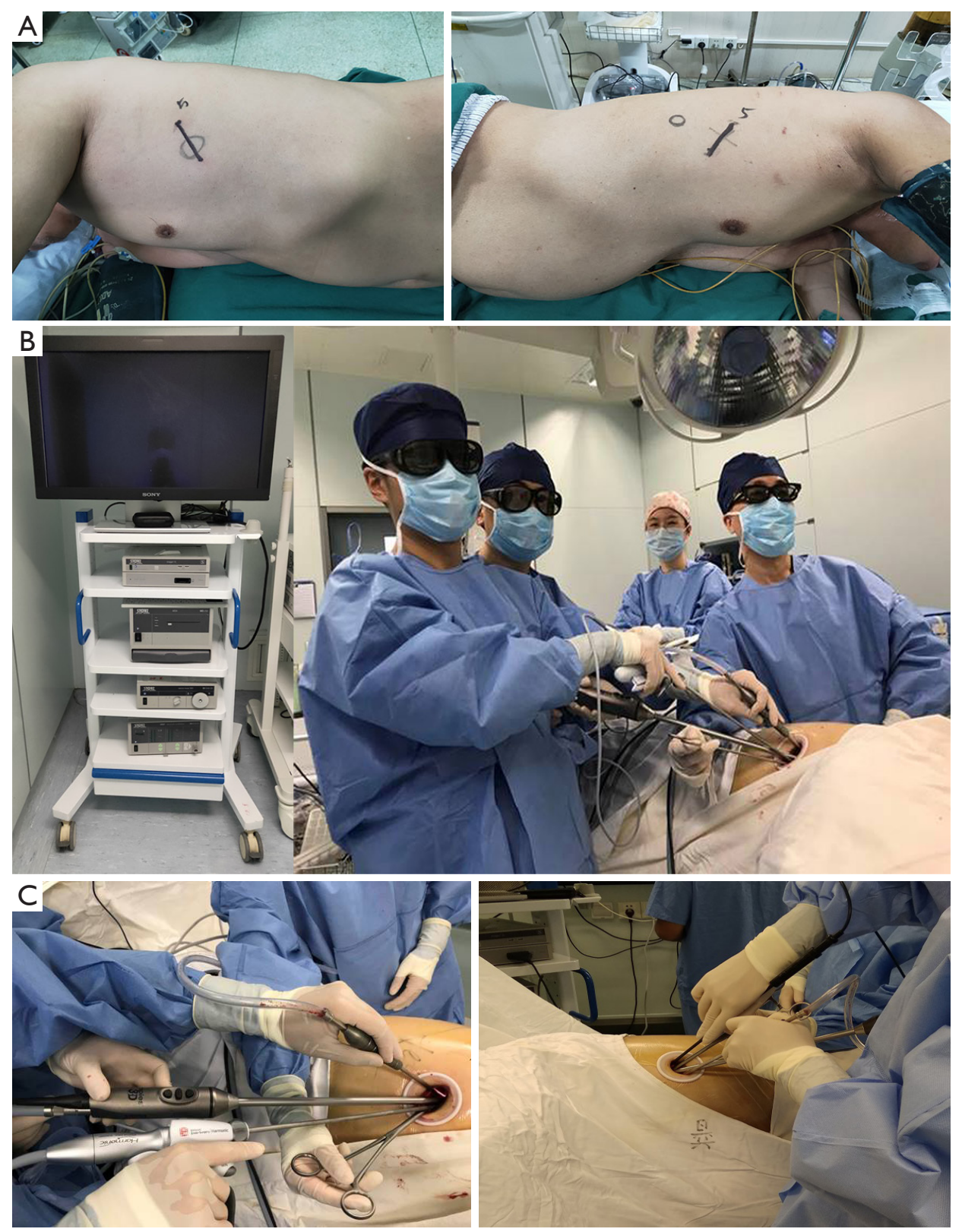

Figure 2 The surgical incision (A), the 3D uniportal VATS system and the position of thoracic surgeons (B), the position of surgical instruments $(\mathrm{C})$.

single-port one $(\mathrm{P}<0.001)($ Table 2$)$.

\section{Subgroup analysis for perioperative outcomes of $3 D$ single- port VATS}

We further divided our patients into several subgroups, including lobectomy, segmentectomy.

In the subgroup analysis of lobectomy, 3D single-port
VATS showed similar operative time and ability of lymph node dissection against with c-VATS, all of which were better than single-port VATS. As for the blood loss and conversion to open thoracotomy, our 3D single-port VATS was in between c-VATS and single-port VATS. As to the postoperative data, 3D single-port VATS demonstrated less drainage time compared with other two approaches. However, our 3D single-port VATS as well as c-VATS 
Table 1 Clinical characteristics

\begin{tabular}{|c|c|c|c|c|}
\hline Characteristics & c-VATS $(n=69)$ & single-port VATS $(n=187)$ & 3D single-port VATS $(n=118)$ & $P$ \\
\hline Male & $24(34.8)$ & $75(40.1)$ & $49(41.5)$ & 0.646 \\
\hline Female & $45(65.2)$ & $112(59.9)$ & $69(58.5)$ & \\
\hline Age (mean \pm SD) (years) & $57.3(10.6)$ & $57.1(12.4)$ & $54.5(10.7)$ & 0.116 \\
\hline No & $62(89.9)$ & $172(92.0)$ & $94(79.7)$ & 0.005 \\
\hline Yes & $7(10.1)$ & $15(8.0)$ & $24(20.3)$ & \\
\hline Preoperative FEV1 (mean \pm SD) $(\mathrm{L})$ & $98.6(8.6)$ & $80.0(11.1)$ & $102.1(7.0)$ & $<0.001$ \\
\hline Tumor size (mean \pm SD) $(\mathrm{mm})$ & $14.8(7.4)$ & $15.8(9.2)$ & $14.4(6.6)$ & 0.330 \\
\hline SCC & $3(4.3)$ & $8(4.3)$ & $4(3.4)$ & \\
\hline Others & $2(2.9)$ & $4(2.1)$ & $5(4.2)$ & \\
\hline \multicolumn{5}{|l|}{ Resection (n, \%) } \\
\hline Lobectomy & $43(62.3)$ & $88(47.1)$ & $75(63.6)$ & $<0.001$ \\
\hline Segmentectomy & $10(14.5)$ & $38(20.3)$ & $13(11.0)$ & \\
\hline WR & $8(11.6)$ & 55 (29.4) & $20(16.9)$ & \\
\hline Others & 8 (11.6) & $6(3.2)$ & $10(8.5)$ & \\
\hline \multicolumn{5}{|l|}{ c-stage (n, \%) } \\
\hline plA1 & $31(44.9)$ & 73 (39.0) & $46(39.0)$ & 0.009 \\
\hline plA2 & $19(27.6)$ & $54(28.9)$ & $48(40.7)$ & \\
\hline plA3 & $11(16.0)$ & $14(7.5)$ & $12(10.2)$ & \\
\hline plB & $5(7.2)$ & $18(9.6)$ & 7 (5.9) & \\
\hline Others & $3(4.3)$ & $28(15.0)$ & $5(4.2)$ & \\
\hline
\end{tabular}

VATS, video-assisted thoracic surgery; FEV1, forced expiratory volume in 1 second; ADC, lung adenocarcinoma; SCC, squamous cell carcinoma; WR, wedge resection. 
Table 2 Perioperative outcomes for clinical stage I patients with c-VATS, single-port VATS and 3D single-port VATS

\begin{tabular}{|c|c|c|c|c|}
\hline & $c-$ VATS $(n=69)$ & $\begin{array}{l}\text { single-port VATS } \\
\qquad(n=187)\end{array}$ & $\begin{array}{l}\text { 3D single-port VATS } \\
\qquad(\mathrm{n}=118)\end{array}$ & $\mathrm{P}$ \\
\hline \multicolumn{5}{|l|}{ Intraoperative data } \\
\hline Operation time (mean $\pm \mathrm{SD})(\mathrm{min})$ & $88.7(32.4)$ & $97.2(43.0)$ & $93.2(30.2)$ & 0.247 \\
\hline Blood loss (mean $\pm \mathrm{SD})(\mathrm{mL})$ & $63.0(56.0)$ & $82.8(52.9)$ & $75.8(67.2)$ & 0.055 \\
\hline Conversion to open thoracotomy $(\mathrm{n}, \%)$ & $4(5.8)$ & $1(0.5)$ & $2(1.7)$ & 0.022 \\
\hline \multicolumn{5}{|l|}{ Postoperative data } \\
\hline Drainage duration (mean $\pm \mathrm{SD}$ ) (days) & $3.0(1.1)$ & $3.0(1.2)$ & $2.7(1.1)$ & 0.109 \\
\hline
\end{tabular}

VATS, video-assisted thoracic surgery; c-VATS, conventional VATS; LOS, length of hospital stay.

Table 3 Subgroup analysis of perioperative outcomes for clinical stage I patients underwent lobectomy with c-VATS, single-port VATS and 3D single-port VATS

\begin{tabular}{|c|c|c|c|c|}
\hline & c-VATS $(n=43)$ & single-port VATS $(n=88)$ & 3D single-port VATS $(n=75)$ & $P$ \\
\hline Operation time (mean $\pm \mathrm{SD}$ ) (min) & $91.8(25.2)$ & $118.0(36.1)$ & $100.0(24.3)$ & $<0.001$ \\
\hline Blood loss (mean $\pm \mathrm{SD})(\mathrm{mL})$ & $57.0(17.5)$ & $106.8(50.8)$ & 76.7 (38.8) & $<0.001$ \\
\hline $\begin{array}{l}\text { The number of dissected lymph nodes } \\
\text { (mean } \pm \text { SD) }\end{array}$ & $11.0(4.0)$ & $9.1(5.0)$ & $11.9(6.4)$ & 0.005 \\
\hline \multicolumn{5}{|l|}{ Postoperative data } \\
\hline Drainage duration (mean $\pm \mathrm{SD}$ ) (days) & $3.0(0.9)$ & $3.3(1.2)$ & $2.7(1.1)$ & 0.010 \\
\hline LOS (mean \pm SD) (days) & $4.6(1.1)$ & $3.3(1.2)$ & $4.5(1.2)$ & $<0.001$ \\
\hline
\end{tabular}

VATS, video-assisted thoracic surgery; c-VATS, conventional VATS; LOS, length of hospital stay.

showed similar duration of hospital stays, all of which was statistically longer than single-port VATS $(\mathrm{P}<0.001)$ (Table 3).

While in the subgroup analysis of segmentectomy, $3 \mathrm{D}$ single-port VATS showed comparable perioperative outcomes against c-VATS (Table 4).

\section{Discussions}

VATS, initially described for lung cancer resection, has been rapidly developed since the 1990`s $(1,8)$. Starting from traditional three or four incisions, the VATS operation has been revolutionized into single-port incision in recent years (9-11). Compared with multi-incision operation, single-port VATS has been declared as a promising minimally invasive surgical choice for early-stage lung cancer patients due to less intercostal space involved, less postoperative pain feeling, lower rate of morbidity and much more satisfied perioperative outcomes (12-14). The $3 \mathrm{D}$ visualization system, firstly reported by Dr. Dickhoff (6), has been gradually applied into video-assisted thoracoscopic surgery for a reduction of surgical time, better depth of visualization 
Table 4 Subgroup analysis of perioperative outcomes for clinical stage I patients underwent segmentectomy with c-VATS, single-port VATS and $3 \mathrm{D}$ single-port VATS

\begin{tabular}{|c|c|c|c|c|}
\hline & c-VATS $(n=10)$ & Single-port VATS $(n=38)$ & 3D single-port VATS $(n=13)$ & $\mathrm{P}$ \\
\hline Operation time (mean \pm SD) (min) & $92.3(31.0)$ & $107.2(31.5)$ & $110.0(20.1)$ & 0.301 \\
\hline Blood loss (mean $\pm \mathrm{SD})(\mathrm{mL})$ & $55.0(15.8)$ & $92.6(30.5)$ & $107.7(178.9)$ & 0.326 \\
\hline $\begin{array}{l}\text { The number of dissected lymph nodes } \\
\text { (mean } \pm \text { SD) }\end{array}$ & $7.1(3.5)$ & $6.5(6.5)$ & $7.6(3.8)$ & 0.826 \\
\hline \multicolumn{5}{|l|}{ Postoperative data } \\
\hline Drainage duration (mean \pm SD) (days) & $3.2(0.8)$ & $2.8(0.8)$ & $2.8(0.8)$ & 0.313 \\
\hline LOS (mean \pm SD) (days) & $4.4(1.2)$ & $2.7(0.8)$ & $4.3(1.1)$ & $<0.001$ \\
\hline
\end{tabular}

VATS, video-assisted thoracic surgery; c-VATS, conventional VATS; LOS, length of hospital stay.

in comparison with traditional 2D VATS $(15,16)$. What's more, it also provided our clinicians a perfect substitution for patients when robotic-assisted thoracoscopic surgery was not permitted.

Hence, the combination of single-port VATS and 3D visualization system, which was defined as $3 \mathrm{D}$ single-port VATS, theoretically obtained the obvious advantages from these two promising procedures. However, the present articles about the 3D single-port VATS still very limited. Therefore, our research could become the first original attempt focusing on this new technique.

c-VATS, including three-port and four-port surgery, as well as the conventional single-port VATS, has been widely accepted when treating with early-stage lung cancer which was confirmed feasible, safe, and comparable to the open technique (17). Inspiringly, our 3D single-port VATS elucidated quite similar perioperative outcomes when compared with c-VATS and single-port VATS among the intraoperative data including the average time of surgical operation, the volume of blood loss and the postoperative data including the average time of drainage duration and postoperative complications according to our present analysis. What's more, 3D single-port VATS even statistically showed comparable or potentially better lymph node dissection against c-VATS which might correlate with the technological superiority of vertical and stereoscopic feeling and vision, which could not be obtained when only $3 \mathrm{D}$ visualization was performed $(15,16)$. In addition, the conversion to open thoracotomy as well as the postoperative complications and hospital stays was similar between 3D single-port VATS and c-VATS. Therefore, 3D singleport VATS totally demonstrated high quality of operability and low rate of perioperative complications in line with traditional VATS and single-port VATS.

Taking account of different surgical procedures, we found out that 3D single-port VATS still took its advantage of lymph node dissection and possessed shorter drainage duration and similar postoperative complications in comparison with c-VATS and single-port VATS when lobectomy was conducted $(12,18,19)$. What's more, the operation time and blood loss of 3D single-port VATS was much better than single-port VATS and statistically close to c-VATS, which also reflected the relative reliability and quality of 3D single-port VATS. Among segmentectomy subgroup, 3D single-port VATS borne comparison with c-VATS and single-port VATS among both intraoperative and postoperative clinical outcomes except hospital stays. Thus, this new technique, 3D single-port VATS, maintained its own comparability and feasibility of excellent safety and perioperative outcomes when routine thoracic operations were performed.

There were still several limitations in this research. First of all, it was a retrospective research which was analyzed from single center database, thus the biases were naturally unavoidable and the randomized clinical trial was strongly needed in further investigation. Second, there were only 374 patients selected in our research. Inadequate candidates might result in relatively less power of persuasion. Herein, large amounts of qualified patients should be enrolled in future verification. Third, what we focused in this study 
was perioperative outcomes and the recurrence and overall survival should be considered for the comparison between our 3D single-port VATS and c-VATS as well as single-port VATS in nearly future.

In conclusions, 3D single-port VATS, integrating the advantages of single-port VATS and three-dimensional vision of 3 D VATS $(20,21)$, targeting both the small incision with one single port and the precise resection with $3 \mathrm{D}$ visualization which represented the ideal of minimally invasive surgery and the precision medicine (22), was a safe and feasible technique and is promising for next-generation thoracoscopic surgery.

\section{Acknowledgments}

Funding: This study was supported by the National Natural Science Foundation of China (81572693).

\section{Footnote}

Reporting Checklist: The authors have completed the STROBE reporting checklist. Available at http://dx.doi. org/10.21037/jtd-19-3465

Data Sharing Statement: Available at http://dx.doi. org/10.21037/jtd-19-3465

Peer Review File: Available at http://dx.doi.org/10.21037/jtd19-3465

Conflicts of Interest: All authors have completed the ICMJE uniform disclosure form (available at http://dx.doi. org/10.21037/jtd-19-3465). The authors have no conflicts of interest to declare.

Ethical Statement: The authors are accountable for all aspects of the work in ensuring that questions related to the accuracy or integrity of any part of the work are appropriately investigated and resolved. This retrospective study was approved by the Institutional Ethics Committee of Shanghai Chest Hospital (KS (Y) 1803), which was in line with the 1964 Helsinki Declaration (as revised in 2013). The written informed consent was not needed for this research.

Open Access Statement: This is an Open Access article distributed in accordance with the Creative Commons Attribution-NonCommercial-NoDerivs 4.0 International
License (CC BY-NC-ND 4.0), which permits the noncommercial replication and distribution of the article with the strict proviso that no changes or edits are made and the original work is properly cited (including links to both the formal publication through the relevant DOI and the license). See: https://creativecommons.org/licenses/by-nc-nd/4.0/.

\section{References}

1. Roviaro G, Rebuffat C, Varoli F, et al. Videoendoscopic pulmonary lobectomy for cancer. Surg Laparosc Endosc 1992;2:244-7.

2. Yan TD, Cao C, D'Amico TA, et al. Videoassisted thoracoscopic surgery lobectomy at 20 years: a consensus statement. Eur J Cardiothorac Surg 2014;45:633-9.

3. Villamizar NR, Darrabie MD, Burfeind WR, et al. Thoracoscopic lobectomy is associated with lower morbidity compared with thoracotomy. J Thorac Cardiovasc Surg 2009;138:419-25.

4. Bendixen M, Jørgensen OD, Kronborg C, et al. Postoperative pain and quality of life after lobectomy via videoassisted thoracoscopic surgery or anterolateral thoracotomy for early stage lung cancer: a randomised controlled trial. Lancet Oncol 2016;17:836-44.

5. Kumar A, Asaf BB. Robotic thoracic surgery: the state of the art. J Minim Access Surg 2015;11:60.

6. Dickhoff C, Li WW, Symersky P, et al. Feasibility of 3-dimensional video-assisted thoracic surgery (3D-VATS) for pulmonary resection. Ann Surg Innov Res 2015;9:8.

7. Gonzalez-Rivas D, Fernandez R, Fieira E, et al. Uniportal video-assisted thoracoscopic bronchial sleeve lobectomy: first report. J Thorac Cardiovasc Surg 2013;145:1676-7.

8. Landreneau RJ, Mack MJ, Hazelrigg SR, et al. Videoassisted thoracic surgery: basic technical concepts and intercostal approach strategies. Ann Thorac Surg 1992;54:800-7.

9. McKenna RJ Jr, Houck W, Fuller CB. Video-assisted thoracic surgery lobectomy: experience with 1,100 cases. Ann Thorac Surg 2006;81:421-5.

10. Gonzalez-Rivas D, Paradela M, Fieira E, et al. Single incision video-assisted thoracoscopic lobectomy: initial results. J Thorac Cardiovasc Surg 2012;143:745-7.

11. Rocco R, Rocco G. Future study direction on single port (uniportal) VATS. J Thorac Dis 2016;8:S328-32.

12. Gonzalez-Rivas D, Paradela M, Fernandez R, et al. Uniportal video-assisted thoracoscopic lobectomy: two years of experience. Ann Thorac Surg 2013;95:426-32.

13. Tamura M, Shimizu Y, Hashizume Y. Pain following 
thoracoscopic surgery: retrospective analysis between single-incision and three-port video-assisted thoracoscopic surgery. J Cardiothorac Surg 2013;8:153.

14. Jutley RS, Khalil MW, Rocco G. Uniportal vs standard three-port VATS technique for spontaneous pneumothorax: comparison of post-operative pain and residual paraesthesia. Eur J Cardiothorac Surg 2005;28:43-6.

15. Dong S, Yang XN, Zhong WZ, et al. Comparison of three-dimensional and two-dimensional visualization in video-assisted thoracoscopic lobectomy. Thorac Cancer 2016;7:530-4.

16. Bagan P, De Dominicis F, Hernigou J, et al. Complete thoracoscopic lobectomy for cancer: comparative study of three-dimensional high-definition with two-dimensional high-definition video systems. Interact Cardiovasc Thorac Surg 2015;20:820-3.

17. Cheng AM, Wood DE. VATS versus open surgery for lung cancer resection: moving beyond the incision. J Natl Compr Canc Netw 2015;13:166-70.

Cite this article as: Wang Y, Wang Z, Yao F. The safety and feasibility of three-dimension single-port video-assisted thoracoscopic surgery for the treatment of early-stage lung cancer. J Thorac Dis 2020;12(12):7257-7265. doi: 10.21037/jtd-193465
18. Jiao P, Wu QJ, Sun YG, et al. Comparative study of three-dimensional versus two-dimensional video-assisted thoracoscopic two-port lobectomy. Thorac Cancer 2017;8:3-7.

19. Gonzalez D, De la Torre M, Paradela M, et al. Videoassisted thoracic surgery lobectomy: 3-year initial experience with 200 cases. Eur J Cardiothorac Surg 2011;40:e21-8.

20. Usta TA, Ozkaynak A, Kovalak E, et al. An assessment of the new generation three-dimensional high definition laparoscopic vision system on surgical skills: a randomized prospective study. Surg Endosc 2015;29:2305-13.

21. Rocco G. One-port (uniportal) video-assisted thoracic surgical resections-a clear advance. J Thorac Cardiovasc Surg 2012;144:S27-31.

22. Cheng X, Onaitis MW, D'amico TA, et al. Minimally Invasive Thoracic Surgery 3.0: Lessons Learned From the History of Lung Cancer Surgery. Ann Surg 2018;267:37-8. 